\title{
EDITORIAL
}

\section{Viruses and idiopathic pulmonary fibrosis}

\author{
J.J. Egan*, A.A. Woodcock*, J.P. Stewart\#
}

Idiopathic pulmonary fibrosis (IPF) is an increasingly recognized problem with a generally poor prognosis [1]. Fifty per cent of patients diagnosed as having IPF may be expected to die within 4 yrs of the diagnosis [2]. Although termed idiopathic or cryptogenic it is increasingly acknowledged that an occult inhaled environmental injury precipitates a common histological response, which manifests as the heterogeneous clinical syndrome, IPF [3, 4].

Since many patients date the onset of their symptoms to a viral infection or a "cold", there has been a suggestion that IPF may be an expression of injury precipitated or potentiated by a diagnostically occult viral infection. Previously, hepatitis C virus (HCV) [5] and Epstein-Barr virus (EBV) [6] have been implicated in the aetiology of IPF, and in this issue KuwANO et al. [7] present data evaluating adenovirus as a factor in the aetiology of IPF. Such viruses have the ability to actively replicate and to assume an endogenous latent state (adenovirus, EBV) or a state of chronic infection (HCV) [8]. The study by KuwANO et al. [7] highlights the difficulties in investigating and interpreting findings related to viruses and IPF. With the advent of highly sensitive molecular based diagnostic techniques, there is the potential for erroneous associations between virus and conditions of unclear aetiology, such as IPF. This review will attempt to place in context the identification and potential role of viruses in patients with IPF.

\section{Hepatitis C virus}

$\mathrm{HCV}$, a ribonucleic acid (RNA) virus, is now recognized as the major cause of non-A, non-B transfusion-associated hepatitis [9]. With improved diagnostic techniques, $\mathrm{HCV}$ infection is increasingly identifiable and is recognized as being associated with conditions other than hepatitis. The background rate of HCV infection is important in interpreting the relationship between $\mathrm{HCV}$ and extra-hepatic disease. Of people exposed to HCV, $50-70 \%$ may be expected to develop chronic infection [9]. This contrasts with viruses such as adenovirus and EBV where almost $100 \%$ of the population would be expected to have experienced an acute infection.

There is controversy as to whether IPF is associated with HCV. UeDA et al. [5] first suggested a relationship between IPF and HCV infection by studying 66 Japanese patients with a clinical diagnosis of IPF, using the first

*North West Lung Centre, Wythenshawe Hospital, Manchester, UK. \#Dept of Veterinary Pathology, Royal (Dick) School of Veterinary Studies, University of Edinburgh, Edinburgh, UK. Correspondence: J.J. Egan, North West Lung Centre, Wythenshawe Hospital, Southmoor Road, Manchester M23 9LT, UK. generation enzyme-linked immunosorbent assay (ELISA) tests for evidence of HCV infection. Twenty eight per cent of the IPF patients studied were found to be HCV antibody positive. Confirmatory testing using recombinant immunoblotting assay (RIBA) was used, and 12 of the 19 index cases were found to be RIBA positive. Unfortunately, in this study it was not specified which RIBA assay was used. The study was then refuted by IRVING et al. [10] who studied stored sera from 62 patients in the UK with a clinical diagnosis of IPF. This study utilized the next, or "second generation" ELISA tests and RIBA for four HCV antigens, C100, 5-1-1, C33 and C22. IRving et al [10] found equivocal evidence of $\mathrm{HCV}$ antibody in only one patient, and confirmatory reverse transcriptase polymerase chain reaction (RT/PCR) was negative. The apparent disparity between these two studies can be explained by the high false-positive rates for the first generation ELISA tests used by UEDA et al. [6]. False-positive results can occur with raised immunoglobulin $\mathrm{G}$ ( $\mathrm{IgG}$ ) levels, which are recognized in approximately $50 \%$ of IPF patients [5, $10]$.

The difficulties in interpretation of HCV and IPF are further emphasized by MeLiConi et al. [11], who studied 60 Italian patients. Control groups included 130 patients with obstructive and suppurative lung disease and 4,614 blood donors. The blood donors, as expected, had a lower rate $(0.3 \%)$ of HCV positivity than the general population. Of the IPF patients, eight of the $60(13 \%)$ had evidence of HCV infection, using second generation ELISA tests. All eight IPF patients were RIBA positive and had evidence of HCV RNA by RT/PCR which did not differ significantly from the $6 \%$ of patients in the control group of mixed lung diseases who were also $\mathrm{HCV}$ positive. Multiple hospital admissions, a risk factor for HCV exposure, was common to both the IPF group and the mixed lung disease group [11].

The study of Meliconi et al. [11] clarified the issue of diagnostic techniques, but emphasized that the baseline prevalence of $\mathrm{HCV}$ infection in the population studied determines the results. In the USA and western Europe, the prevalence of $\mathrm{HCV}$ positivity is approximately $1 \%$, in northern Italy it is $3.4 \%$ and in some parts of Japan it is as high as $30 \%[11,12]$. Therefore, it is most likely that the relationship between IPF and HCV is spurious and reflects the background rate of HCV infection.

\section{Adenovirus}

Adenovirus is a ubiquitous virus recognized as causing a spectrum of clinical disease, including both upper and lower respiratory tract infections from which most 
people recover. MATSUSE et al. [13] have demonstrated using the polymerase chain reaction (PCR) that adenoviral deoxyribonucleic acid (DNA) exists in the lower respiratory tract of human lungs. KuwANO et al. [7], with nested PCR, have studied the prevalence of adenovirus DNA in the lung tissue of patients with IPF, using primers directed against the early gene $E 1 A$, a gene that facilitates cell transformation [8]. In this study, $16 \%$ of IPF cases had evidence of adenovirus DNA. Using nested PCR with an in vitro sensitivity of one single copy of adenovirus DNA, the prevalence is unexpectedly low, because the lower respiratory tract is a potential reservoir for adenovirus [13].

The low rate of adenovirus DNA positivity may be explained firstly by enhanced clearance of infected cells by the background inflammatory and repair process. This process has been proposed to explain the low prevalence of adenovirus DNA in follicular bronchiectasis [14]. Secondly, the low prevalence of adenovirus DNA in IPF may be due to sampling error by the use of transbronchial biopsy for the acquisition of lung tissue. Three transbronchial biopsies in the setting of lung fibrosis are probably not comparable to studying surgically resected tissue specimens. In the study by MATSUSE et al. [13] using primers for $E 1 A$ adenoviral DNA, serial tissue sections alternated between PCR positivity and PCR negativity. This suggested that E1A DNA was randomly present in the bronchial epithelial cells. A similar distribution in the lung of IPF patients would, therefore, explain the low prevalence in tissue obtained by transbronchial biopsy specimens despite the sensitivity of nested PCR.

The finding by KuwANo et al. [7] that adenovirus DNA is more common in those patients receiving corticosteroid therapy $(67 \%)$ compared to those not receiving therapy $(10 \%)$ is interesting. Considering that transbronchial biopsies may have underestimated the incidence of adenovirus DNA positivity, this may indicate that the viral load in such immunocompromised patients is higher than normal. Potentially, this is an important finding, which suggests that adenovirus replication is promoted by immunosuppression. Whether viral replication in the presence of immunosuppression then contributes to disease progression, could only be proven by demonstrating a response to antiviral therapy.

Conflicting data have been presented on the application of antiviral therapy against adenovirus in patients with IPF. PRIETO et al. [15] described a case in which the patient responded to the administration of nebulized ribivarin. The case appeared to be consistent with a pattern of cellular, usual interstitial pneumonia (UIP). If it is assumed that cellular UIP represents an "early" phase of IPF, then such a response to ribivarin would support the hypothesis that adenovirus infection was involved in the initiation of the process that resulted in IPF. In contrast, Agusti et al. [16], studied 10 immunocompromised patients with advanced IPF and observed no benefit from aerosolized ribivarin. Although one patient exhibited an objective improvement, it is often difficult to demonstrate any therapeutic benefit in patients with advanced IPF because of the degree of pulmonary remodelling that has occurred [17]. Therefore, to date there is no clear evidence of a response to therapy for adenovirus in IPF patients.

\section{Epstein-Barr virus}

EBV is a gamma herpes virus that is present in $>90 \%$ of the general population [8]. Acute infection may manifest as the syndrome of infectious mononucleosis. Following acute infection, EBV assumes a latent state. Whether epithelial cells or B-lymphocytes are the site of EBV persistence is an area of controversy [18]. Host T-cell mediated immune surveillance maintains EBV latency. Despite apparent host immune competence, EBV has oncogenic potential and is associated with Burkitt's lymphoma, Hodgkin's lymphoma and nasopharyngeal carcinoma [19]. Overt modification of the host immune state (human immunodeficiency virus (HIV), following transplantation) can allow latent EBV-driven B-cell proliferation, which manifests as lymphoproliferative disease. Immunosuppression can also give rise to a productive EBV replication in epithelial cells, as seen in oral hairy leukoplakia (OHL) [19].

EBV was first implicated in the aetiology of IPF in 1984 by a French study based on EBV blood serology [6]. Elevated levels of $\operatorname{IgG}$ and immunoglobulin A ( $\operatorname{IgA}$ ) against viral capsid antigen (VCA) were observed in 11 patients with IPF. Although, in general, serological testing for EBV infection has a low sensitivity and specificity, the specificity of IgA against VCA is high and suggests the presence of active EBV replication at an epithelial site [20]. Subsequently, a tissue-based study was undertaken using immunohistochemistry [21]. Of 20 open lung biopsies taken from patients with IPF, 14 had positive staining for both VCA and the membrane antigen gp340/220, EBV antigens expressed during viral replication. These findings were compared to resected tissue taken from a control group that was predominantly composed of patients undergoing surgical treatment of lung cancer. In the control group, lung tissue remote from the neoplasia was studied for EBV. Of 21 controls studied, two were EBV VCA and gp340/ 220 positive [21].

EBV antigen-positive staining needs to be interpreted in the context of a number of factors, including whether the viral antigens studied are expressed during viral latency or viral replication [8]. The most commonly used reagents for the diagnosis of EBV are those antibodies specific for proteins associated with EBV transformation, which are expressed during virus latency. These include monoclonal antibodies specific for EBV nuclear antigen (EBNA) 2 and latent membrane protein (LMP), which are able to detect EBV-transformed proliferating cells [22]. Examples of this include the detection of EBV in association with the post-transplant lymphoma and lymphocytic interstitial pneumonia [23].

In contrast, antibodies specific for cells containing EBV that is undergoing productive replication, i.e. producing viral particles, are also available in a diagnostic context. Examples of these include antibodies specific for immediate early protein BZLF1, components of the VCA or the membrane antigen gp340/220 [24]. These reagents are used in the detection of productively replicating EBV in epithelial lesions such as oral hairy leukoplakia, and have been studied in IPF [21, 25].

The interpretation of EBV positivity is further influenced by the target cell type of interest [8]. The infected host cell characteristics influence the phase of the EBV 
cell cycle. EBV infection of undifferentiated basal epithelial cells or B-lymphocytes results typically in EBV establishing a latent phase characterized by expression of EBERs (EBV-related small messenger RNA detected by in situ hybridization) and the EBNA/LMP antigens $[8,26]$. Conversely, viral replication characterized by VCA and membrane antigen expression typically occurs in terminally differentiated epithelial cells, including the parotid gland, OHL and, it would appear, in IPF $[21,25]$.

A further difficulty in interpreting immunohistochemistry is that there is the potential for antibodies directed against viral antigens to cross react with host antigens ("molecular mimicry") [27]. Up to 5\% of all monclonal antibodies developed for the identification of viruses react against autoantigens. In order to minimize this possibility, two antibodies directed against two different EBV antigens (VCA, gp340/220) were used in the tissuebased study of EBV in lung tissue [21].

Another technique for EBV detection and cellular localization is the use of in situ hybridization (ISH) for EBERs [26]. Whilst ISH for EBER and immunohistology have the advantage of allowing localization of EBV, they do not necessarily complement or mirror each other. EBERs are not expressed in lesions of active viral replication such as OHL, where the use of antibodies are more informative [25]. Such a biological model as OHL, in which EBV viral replication occurs in differentiated epithelial cells in the absence of EBER expression may be comparable to EBV replication in IPF, in which EBER expression is absent in cells expressing VCA and membrane antigen (unpublished observations). The identification of EBV-related antigens, therefore, demands the application of corroborative diagnostic techniques.

The PCR is an extremely sensitive technique that has been applied in the diagnostic context for a number of viruses. Preliminary data has been presented on PCR for EBV DNA in IPF. In a small study of lung tissue $(\mathrm{n}=4)$, PCR for the EBV gene $B A M W$ was negative [28]. In contrast, in a study of 20 cases of IPF using nested PCR with a sensitivity of 1-10 copies of EBV DNA (RAJI I), 11 cases had evidence of EBV DNA (versus 1 of 8 normals and 1 of 8 patients with sarcoidosis) [29]. Another group has also observed that six of 12 cases with IPF were EBV DNA PCR positive [30]. These study differences may reflect: EBV activity in discrete areas of alveolar tissue; patient selection; or the sensitivity of the PCR assay. A major problem with PCR for the diagnosis of EBV is the ubiquitous nature of the virus. EBV DNA can be detected in the blood of most individuals and the lung is recognized as a reservoir for EBV [31].

Quantitation of the EBV DNA load by PCR may allow a study of the relationship between the viral load and IPF, and has proven useful in assessing individuals in the context of post-transplant lymphoproliferative disease [32]. A study of quantitative PCR in IPF would be a laborious and difficult study in a heterogeneous group of individuals. Therefore, the study of EBV in animal models may give insight into the behaviour of EBV in lung tissue. EBV, like all gamma herpes viruses, has an extremely narrow host range. The best-known model for EBV infection, the cotton top tamarin, does not breed well in captivity and is an endangered species. The mouse model of murine gamma herpes virus 68
(MHV68) infection, which, like EBV, is transmitted via the nasal route, results in an interstitial pneumonia and transient splenomegaly reminiscent of infectious mononucleosis. It then becomes latent in B-cells, persisting for the lifetime of the mouse, and is associated with the development of lymphoma [33, 34].

The presence of EBV, whether detected by immunohistochemistry or PCR, has to be judged in the context of the presence or absence of immunosuppression. EBVassociated pulmonary fibrosis has also been described in a heart-lung transplant recipient [35]. Such an association in an immunocompromised transplant recipient emphasizes the issue of whether a ubiquitous herpes virus like EBV represents "a passenger or a pathogen" when localized in lung tissue. Further examples of this controversy are with cytomegalovirus (CMV) in acquired immune deficiency syndrome (AIDS) patients and human herpes virus 6 in bone marrow transplant recipients [36, 37]. In the study by Kuwano et al. [7], an increased incidence of adenovirus seen in patients receiving corticosteroid therapy is a further example of this controversy.

If latent viruses such as adenovirus and EBV exist in groups of IPF patients, how might such viruses contribute to disease progression? Firstly, viral proteins that are already present in cells can promote chronic inflammation and repair. For instance, EBV LMP increases class II antigen expression in previously EBV negative B-lymphocytes [38]. Furthermore, viral proteins may promote the persistence of inflammation that was originally initiated by a different (environmental) injury. The repeat GPPAA sequence is observed both in the HLADQ8 $\beta$-chain and the EBV EBNA 3 antigen [27]. This could promote antibody cross-reactivity between viral and host antigen as is seen with CMV infection following solid organ transplantation [39]. Secondly, viral infection may activate type 1 collagen genes in alveolar epithelium. It has been demonstrated that rat neonatal alveolar cells immortalized by the adenoviral $12 \mathrm{SE} 1 \mathrm{~A}$ gene produce large amounts of type 1 collagen [40].

Finally, viral genes may act as transactivating factors. Transactivating factors are nuclear proteins which, because of specific census sequences, bind to or interact with DNA, thereby regulating RNA protein transcription and modifying cell behaviour [41]. Proto-oncogenes are an example of such target genes for viral proteins. Protooncogenes are normal, "wild" growth regulating genes while "mutant" proto-oncogenes are expressed in a deregulated manner and play a role in tumorigenesis. Such oncogenes are expressed in lung tissue. A recent report (KUWANO et al. [42]) suggests that overexpression of wild p53 gene occurs in the lung tissue of IPF patients. This may reflect regulation of cells with damaged DNA. Fibroblasts obtained from patients with Li-Fraumeni syndrome which inherently have $p 53$ mutations, demonstrate in vitro prolongation of their fibroblast life span and, sometimes immortalization of the fibroblast [43].

EBV has the potential to interact with oncogenes. The EBV nuclear antigen (EBNA 5) can form a molecular complex with both the retinoblastoma (RB) gene and p53 gene [44]. The EBV immediate early protein BZLF1 interacts with $p 53$ both in vivo and in vitro [45]. BZLF1 inhibits $p 53$-dependent transactivation. Adenovirus also has the ability to interact with $p 53$ tumour suppressor 
gene [46]. The adenoviral protein $E 1 A$ has the potential to bind to the RB oncogene [47]. The RB gene controls the genesis of the cell replication phase. E1A promotes cell replication and growth by binding to RB.

Therefore, the interaction of viral proteins (transactivating factors) with genes involved in the regulation of cell growth may provide a common mechanism by which different viruses play a role in a single fibroproliferative disease process such as IPF. However, further study is required in this area.

How can one reconcile the concept of virus-mediated IPF and IPF precipitated by an inhaled environmental injury [3, 4, 6, 21]? Within the heterogeneous group of patients labelled as IPF, it is possible that different aetiological groups exist, some with an environmental trigger, and others with a viral trigger. In some IPF patients, a primary environmental injury may be potentiated at a later phase in the disease process by viral replication within the injured tissue. Ultimately each individual or combination of aetiological factors may contribute to a common clinical and histological response to injury.

The application of sensitive diagnostic techniques has allowed the detection of ubiquitous viruses in the lung tissue of patients with IPF. This does not prove cause and effect. The identification of viruses is influenced by many factors, particularly the sensitivity and specificity of the diagnostic techniques, the distribution of the virus within the lung and the presence or absence of immunosuppression.

Mechanisms by which viruses may promote an inflammatory response and influence cell behaviour have been identified. IPF may not necessarily be related to one single virus; rather, different ubiquitous viruses may potentiate the disease process via a common pathway. As many patients deteriorate while receiving immunosuppressant therapy, at issue is whether an increasing viral load may be a cofactor contributing to disease progression. In idiopathic pulmonary fibrosis, a pathogenic role can only be ascribed to viruses if a clinical response is demonstrated by the administration of antiviral therapy.

\section{References}

1. Johnston I, Britton J, Kinnear W, Logan R. Rising mortality from cryptogenic fibrosing alveolitis. $\mathrm{Br}$ Med $\mathrm{J}$ 1990; 301: 1017-1021.

2. Stack BHR, Choo-Kang YFJ, Heard BE. The prognosis of cryptogenic fibrosing alveolitis. Thorax 1972; 27: 535-542.

3. Scott J, Johnston I, Britton J. What causes cryptogenic fibrosing alveolitis? A case control study of environmental exposure to dust. Br Med J 1990; 301: 1015-1017.

4. Hubbard R, Lewis S, Richards K, Johnston I, Britton J. Occupational exposure to metal or wood dust and aetiology of cryptogenic fibrosing alveolitis. Lancet 1996; 347: 284-289.

5. Ueda T, Ohta K, Suzuki N, et al. Idiopathic pulmonary fibrosis and high prevalence of serum antibodies to hepatitis C virus. Am Rev Respir Dis 1992; 146: 266-268.

6. Vergnon JM, Vincent M, De The G, Mornex JF, Weynets P, Brune J. Cryptogenic fibrosing alveolitis and EpsteinBarr virus: an association. Lancet 1984; ii: 768-770.
7. Kuwano K, Nomoto Y, Kunitake R, et al. Detection of adenovirus E1A DNA in pulmonary fibrosis using nested polymerase chain reaction. Eur Respir J 1997; 10: 1445-1449.

8. Hogg JC, Hengle RG. Adenovirus and Epstein Barr Virus in lung disease. Semin Respir Infect 1995; 10: 224-253.

9. Gumber S, Chopra S. Hepatitis C: a multifaceted disease. Ann Intern Med 1995; 123: 615-620.

10. Irving WL, Day S, Johnston IDA. Idiopathic pulmonary fibrosis and hepatitis C virus infection. Am Rev Respir Dis 1993; 148: 1683-1684.

11. Meliconi R, Andreone P, Fasano L, et al. Incidence of hepatitis $\mathrm{C}$ virus infection in Italian patients with idiopathic pulmonary fibrosis. Thorax 1996; 51: 315-317.

12. Kiyosawa K, Tanka E, Sodeyama T, et al. Transmission of hepatitis $\mathrm{C}$ in an isolated area in Japan: community acquired infection. Gastroenterology 1994; 106: 15961602.

13. Matsuse T, Hayashi S, Kuwano K, Keunecke H, Jefferies WA, Hogg JC. Latent adenoviral infection in the pathogenesis of chronic airways obstruction. Am Rev Respir Dis 1992; 146: 177-184.

14. Bateman ED, Hayashi S, Kuwano K, Wilke TA, Hogg JC. Adenoviral infection in follicular bronchiectasis. Am J Respir Crit Care Med 1995; 151: 170-176.

15. Prieto J, Sangro B, Beloqui O. Ribavirin in desquamative interstitial pneumonia. Chest 1988; 93: 446-447.

16. Agusti C, Xaubet A, Ballester E, Alarcon A, Picado C. Aerosolised ribavirin in patients with advanced cryptogenic fibrosing alveolitis: a pilot study. Thorax 1993; 48: 68-69.

17. Cherniack RM, Colby TV, Flint A, et al. Correlation of structure and function in idiopathic pulmonary fibrosis. Am J Respir Crit Care Med 1995; 151: 1180-1188.

18. Niedobitek G, Young LS. Epstein-Barr virus persistence and virus-associated tumours. Lancet 1994; 343: 333-335.

19. Straus SE, Cohen JI, Tosato G, Meier J. Epstein-Barr virus infections: biology, pathogenesis, and management. Ann Intern Med 1993; 118: 45-48.

20. Henle W, Henle G. Epstein Barr virus specific serology in immunologically compromised individuals. Cancer Res 1981; 41: 4222-4225.

21. Egan JJ, Stewart JP, Hasleton PS, Arrand JR, Carroll $\mathrm{KB}$, Woodcock AA. Epstein - Barr virus replication within pulmonary epithelial cells, in cryptogenic fibrosing alveolitis. Thorax 1995; 50: 1234-1239.

22. Stewart JP, Arrand JR. Expression of the Epstein-Barr virus latent membrane protein in nasopharyngeal carcinoma biopsy specimens. Hum Pathol 1993; 24: 239-242.

23. Egan J, Stewart JP, Yonan N, Arrand JP, Woodcock AA. Non Hodgkin lymphoma in heart/lung transplant recipients. Lancet 1994; 1: 481.

24. Hoffman GJ, Lazarowitz SG, Hayward SD. Monoclonal antibody against a 250,000 dalton glycoprotein of Epstein-Barr virus identifies a membrane antigen and a neutralising antigen. Proc Natl Acad Sci USA 1980; 77: 2979-2983.

25. Niedobitek G, Young LS, Lau R, et al. Epstein-Barr infection in oral hairy leukoplakia: virus replication in the absence of a detectable latent phase. J Gen Virol 1991; 72: 3035-3046.

26. Howe JG, Steitz JA. Localisation of Epstein-Barr virusencoded small RNAs by in situ hybridization. Proc Natl Acad Sci 1986; 83: 9006-9010.

27. Parkkonen P, Hyoty H, Ilonen J, Reijonen H, Yla-Herttuala S, LeinikkI P. Antibody reactivity to an Epstein 
barr virus BERF4-encoded epitope occurring also in Asp57 region of HLA-DQ8 B chain. Clin Exp Immunol 1994; 95: 287-293.

28. Wangoo A, Nicholson AG, Diss TC, Farrell PJ, du Bois RM, Shaw RJ. Cryptogenic fibrosing alveolitis does not appear associated with Epstein-Barr virus infection. Thorax 1996; 51: s3: A11.

29. Egan JJ, Stewart JP, Hasleton PS, Nash AA, Woodcock AA. EBV PCR (Raji I) in idiopathic pulmonary fibrosis and sarcoidosis. Am J Respir Crit Care Med 1997; 155(4): A315.

30. Quddus MR, Nayer A, King TC, Jackson CL, Kuhn C. EBV in idiopathic pulmonary fibrosis. United States and Canadian Academy of Pathology 1997; 171A.

31. Lung ML, Lam WK, So SY, Lam WP, Chan KH, Ng MH. Evidence that respiratory tract is major reservoir for Epstein-Barr virus. Lancet 1985; 1: 889-892.

32. Rooney CM, Smith CA, Ng CYC. Use of gene-modified virus specific T-lymphocytes to control EpsteinBarr virus related lymphoproliferation. Lancet 1995; 345: 9-13.

33. Sunil-Chandra NP, Efstathiou S, Arno J, Nash AA. Virological and pathological features of mice infected with murine gamma herpes 68. J Gen Virol 1993; 73: 2347-2356.

34. Nash AA, Usherwood EJ, Stewart JP. Immunological features of murine gamma herpes virus infection. Semin Virol 1996; 7: 125-131.

35. Egan JJ, Stewart JP, Hasleton PS. Epstein Barr Virus associated graft failure following heart lung transplantation. Thorax 1996; 51: 1160-1162.

36. Millar AB, Patou G, Miller RF, et al. Cytomegalovirus in the lungs of patients with AIDS. Respiratory pathogen or passenger? Am Rev Respir Dis 1990; 141: 14741477.

37. Carrigan DR, Drobyski WR, Russler SK, Tapper MA, Knox KF, Ash RC. Interstitial pneumonitis associated with human herpes virus-6 infection after marrow transplantation. Lancet 1991; 338: 147-149.
38. Zhang Q, Brooks L, Busson P, et al. Epstein - Barr virus latent membrane protein 1 increases HLA class II expression in an EBV-negative B-cell line. Eur J Immunol 1994; 24: 1467-1470.

39. Fujinami RS, Nelson JA, Walker L, Oldstone MA. Sequence homology and immunologic cross-reactivity of human cytomegalovirus and HLA-DR B chain: a means for graft rejection and immunosuppression. J Virol 1988; 62: 100-105.

40. Matsui R, Goldstein RH, Mihal K, Brody JS, Steele MP, Fine A. Type I collagen formation in rat type II alveolar cells immortalised by viral gene products. Thorax 1994; 49: 201-206.

41. Pollack PS. Proto-oncogenes and the cardiovascular system. Chest 1995; 107: 826-835.

42. Kuwano K, Kunitake R, Kawasaki M, et al.p21 WAF1/ CIP1/Sdill and p53 expression in association with DNA strand breaks in idiopathic pulmonary fibrosis. Am J Respir Crit Care Med 1996; 154: 477-483.

43. Bischolff FZ, Yim SO, Pathak S, et al. Spontaneous abnormalities in normal fibroblasts from patients with Li-Fraumeni cancer syndrome: aneuploidy and immortalization. Cancer Res 1990; 50: 7979-7984.

44. Szekely L, Selivanova G, Magnusson KP, Klein G, Wiman KG. EBNA-5, an Epstein barr virus encoded nuclear antigen, binds to the retinoblastoma and p53 proteins. Proc Natl Acad Sci USA 1993; 90: 5455-5459.

45. Zhang Q, Gutsch D, Kenny S. Functional and physical interaction between p53 and BZLF1: implications for Epstein Barr virus latency. Mol Cell Biol 1994; 14: 1929-1938.

46. Sabbatini P, Chiou SK, Roa L, White E. Modulation of p53-mediated transcriptional repression and apoptosis by the adenovirus E1B 19K protein. Mol Cell Biol 1995; 15: $1060-1070$.

47. Whyte P, Buchovich KG, Horowitz JM, et al. Association between an oncogene and an anti-oncogene: the adenovirus E1A protein binds to the retinoblastoma gene product. Nature 1988; 334: 124-129. 